\title{
BMJ Open What drives inappropriate antibiotic dispensing? A mixed-methods study of pharmacy employee perspectives in Haryana, India
}

\author{
Anna K Barker, ${ }^{1}$ Kelli Brown, ${ }^{1}$ Muneeb Ahsan, ${ }^{2}$ Sharmila Sengupta, ${ }^{3}$ \\ Nasia Safdar ${ }^{4,5}$
}

To cite: Barker AK, Brown K, Ahsan M, et al. What drives inappropriate antibiotic dispensing? A mixedmethods study of pharmacy employee perspectives in Haryana, India. BMJ Open 2017;7:e013190 doi:10.1136/bmjopen-2016013190

- Prepublication history and additional material is available. To view please visit the journal (http://dx.doi.org/ 10.1136/bmjopen-2016013190).

Received 27 June 2016 Revised 13 January 2017 Accepted 2 February 2017

CrossMark

For numbered affiliations see end of article.

Correspondence to Dr Nasia Safdar; ns2@medicine.wisc.edu

\section{ABSTRACT}

Objectives: There are only 0.70 licensed physicians per 1000 people in India. Thus, pharmacies are a primary source of healthcare and patients often seek their services directly, especially in village settings. However, there is wide variability in a pharmacy employee's training, which contributes to inappropriate antibiotic dispensing and misuse. These practices increase the risk of antibiotic resistance and poor patient outcomes. This study seeks to better understand the factors that drive inappropriate antibiotic dispensing among pharmacy employees in India's village communities.

Design: We conducted a mixed-methods study of the antibiotic dispensing practices, including semistructured interviews and a pilot cross-sectional Knowledge, Attitudes and Practice survey. All data were transcribed, translated from Hindi into English, and coded for themes.

Setting: Community pharmacies in villages in Haryana, India.

Participants: We recruited 24 community pharmacy employees (all male) by convenience sampling. Participants have a range of characteristics regarding village location, monthly income, baseline antibiotic knowledge, formal education and licensure.

Results: $75 \%$ of pharmacy employees in our study were unlicensed practitioners, and the majority had very limited understanding of antibiotic resistance. Furthermore, only half could correctly define the term antibiotics. All reported that at times they dispensed antibiotics without a prescription. This practice was more common when treating patients who had limited access to a licensed physician because of economic or logistic reasons. Many pharmacy workers also felt pressure to provide shortened medication courses to poorer clientele, and often dispensed only 1 or 2 days' worth of antibiotics. Such patients rarely returned to the pharmacy for the complete course.

Conclusions: This study highlights the need for shortterm, intensive training programmes on antibiotic prescribing and resistance that can be disseminated to village pharmacies. Programme development should take into account the realities of working with poor clientele, especially in areas of limited healthcare access.

\section{Strengths and limitations of this study}

- First study of its kind assessing pharmacy employees' antibiotic dispensing practices in low-resource Indian villages, which constitute $70 \%$ of the nation's population.

- Usage of mixed methodology allows for more in-depth investigation of how social determinants of health affect antibiotic dispensing.

- Our findings illustrate the critical need for development and implementation of a practical antibiotic training programme among village pharmacies.

- Convenience sampling method of recruitment may introduce bias, particularly for quantitative results.

- India is a large and heterogeneous nation; thus, findings may have limited generalisability across all pharmacies in the country.

\section{INTRODUCTION}

Antibiotic dispensing without prescriptions is a common practice in many low-income and middle-income countries. These countries tend to have lower doctor to patient ratios, with doctors especially limited in rural settings. ${ }^{1}{ }^{2}$ In India, there are 0.70 physicians per 1000 people overall, compared with 2.81 in the UK and 2.45 in the USA. ${ }^{1}$ The ratio is even lower in India's villages, which account for $70 \%$ of its population. ${ }^{34}$

Pharmacies become a primary source of healthcare in the context of limited physician access, and patients often seek their services directly. ${ }^{5} 6$ This makes strict enforcement of regulations restricting over the counter dispensing of antibiotics challenging. While overenforcement limits the availability of antibiotics for rural patients, ${ }^{7}$ not enforcing regulations can perpetuate antibiotic overuse and misuse. This is further complicated by the wide variability in pharmacy employees' clinical training. ${ }^{8}$ 
Pharmacists in India are required to have a 2-year Diploma in Pharmacy (D Pharm), 4-year Bachelors in Pharmacy (B Pharm) or one of several graduate pharmacy degrees. The curriculum for degrees in B Pharm and higher prepare students for careers in industry or academia, and most trained practising pharmacists have the 2-year D Pharm degree. ${ }^{9}$ By law, all pharmacies are required to have a licensed pharmacist on staff at all times. In reality, though, many pharmacies employ a D Pharm pharmacist in name only, and those dispensing medications and providing health recommendations often do not have a clinical degree. ${ }^{8}$

The lack of formal health training contributes to inappropriate medication dispensing, which is especially dangerous for antibiotics. Antibiotic misuse has negative consequences at the individual and societal level, contributing to poor patient outcomes and increased risks for drug resistance. Stemming the current rise in antibiotic resistant infections is a top priority of the WHO and many national health agendas. ${ }^{10-14}$ Yet the burden of these infections falls disproportionately on lowincome and middle-income countries. ${ }^{15}$ In India alone, multidrug resistant organisms are responsible for over 58000 neonate deaths annually. ${ }^{16}$

Research into village pharmacies' contributions to antibiotic resistance is lacking. Most studies of inappropriate antibiotic use in Europe and the USA have focused on prescribing, with doctors as the key gatekeepers for medication access. ${ }^{17-20}$ However, recent studies from Spain and Portugal have identified inappropriate dispensing of antibiotics by pharmacists as a nontrivial practice that warrants concern and further evaluation. ${ }^{21-24}$ Studies addressing antibiotic dispensing in low-income and middle-income countries have been conducted primarily in large urban centres, where physicians are more readily available and pharmacy employees without formal training are less likely to serve a primary healthcare role. ${ }^{25-30}$ We conducted a mixedmethods study of village pharmacies in Haryana, India to investigate the factors driving inappropriate antibiotic dispensing. We hypothesised that less formal clinical training, limited village healthcare access and poorer patient clientele would increase inappropriate antibiotic dispensing by pharmacy employees.

\section{METHODS}

We conducted a mixed-methods study of antibiotic dispensing practices among village pharmacies in Haryana, India from July to August 2015. This study was nested within a larger study of antibiotic practices among healthcare professionals and patients.

\section{Pharmacist population}

We recruited 24 village pharmacy employees. All participants completed a cross-sectional survey and 20 completed an individual semistructured interview. At the beginning of the study, four participants were lost to follow-up between their survey and interview date. We subsequently conducted both measures at the same study visit. Recruitment was stopped on reaching theoretical saturation.

Ten urban and rural Haryana villages were selected for study by convenience sampling, based on pre-existing connections with local community members. These study advocates introduced researchers to pharmacy employees and increased community support for the project. Within a given village, we attempted to enrol all eligible employees working at the time of the visit. Anyone dispensing medicine without supervision was eligible. All employees at the pharmacies we visited were male. Pharmacist trainees were excluded, as well as those who did not speak either English or Hindi. Only one person, a trainee, was excluded during study enrolment.

\section{Survey}

We developed a cross-sectional Knowledge, Attitude and Practices survey, adapted from surveys of antibiotics in other low-resource settings. ${ }^{30-33}$ This was finalised by our international study team (USA/India) after review by two pharmacists, two infection control specialists and an epidemiologist. The survey was given as a pilot study to 24 people, including 20 interview participants and 4 additional participants, who were lost to follow-up before their interview. This survey was concurrently pilot tested in two additional populations as part of an overarching study (results not presented). The unvalidated pilot survey is shown in online supplementary 1 .

The goal of the survey was to collect additional data from our interview participants using a structured approach; thus, sample size was driven by the size of the interview population. The survey included 19 open-ended and 29 close-ended questions. Data were collected regarding participants' demographics, health literacy, antibiotic knowledge and typical antibiotic use. This paper presents descriptive statistics based on demographic information and responses to the survey questions: Give your best definition of antibiotics and 'If you had these conditions, would you need antibiotics to treat them?'

\section{Interviews}

We conducted 20 individual interviews. The interview was structured around an initial interview guide (see online supplementary 2), derived from our conceptual framework (figure 1). The discussion of healthcare access included perceived patient healthcare preferences and the interplay between local medical providers and pharmacies. We assessed employees' formal and experiential training, and how this impacted daily practice. We also investigated economic pressures, including both profit-driven pressure to overdispense and pressure from low-income patients to dispense shortened antibiotic courses. 


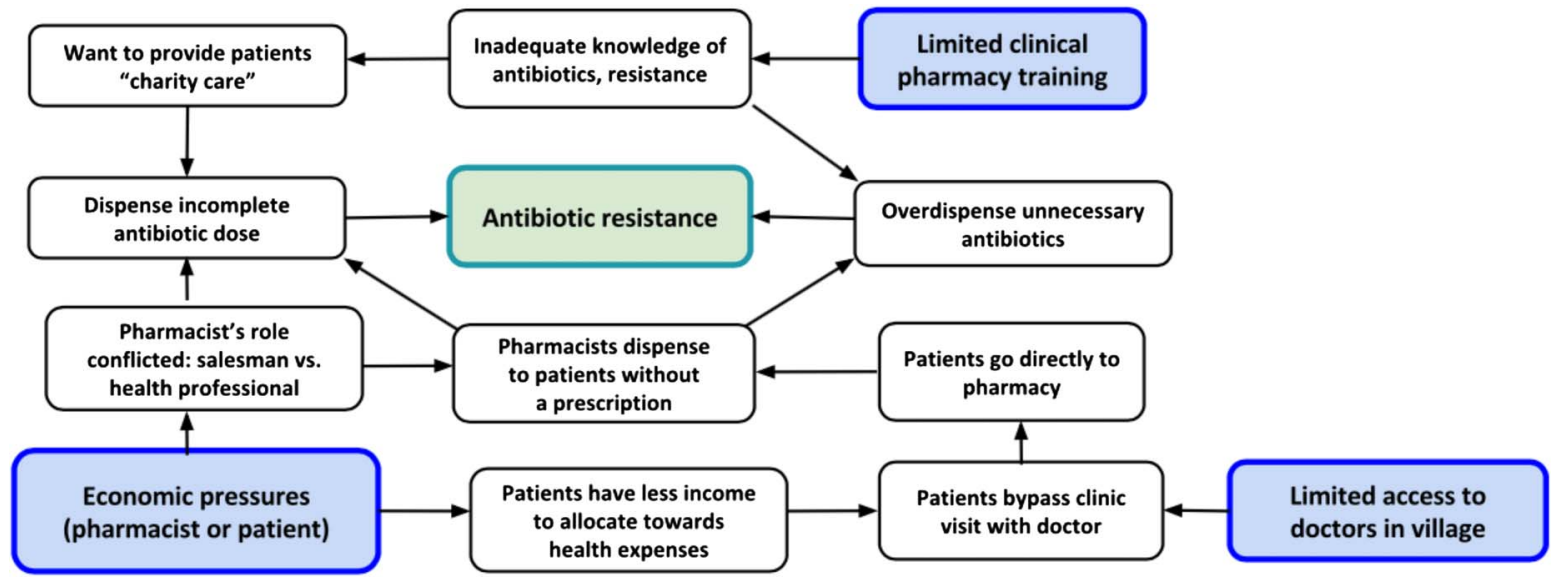

Figure 1 Conceptual framework illustrating relationships between education, economic pressures, healthcare access, pharmacy dispensing patterns and antibiotic resistance.

All interviews were conducted one-on-one by bilingual, English-Hindi speaking members of the study team. Hindi was used as the primary language of discourse. Most interviews lasted $10-15 \mathrm{~min}$. All were audio recorded, transcribed into Hindi and translated into English for analysis.

\section{Analysis}

Preliminary data analysis took place during fieldwork to identify reoccurring themes in employees' responses and determine theoretical saturation. These findings motivated iterative revisions to the interview guide throughout the study. Interview transcripts and openended survey responses were analysed with Nvivo software (V.10.2, QSR International). Responses were coded for themes based on the interview guide and conceptual framework (figure 1). Themes included dispensing in areas of limited healthcare access, clinical knowledge and economic pressures. Data were independently coded by two investigators, who subsequently reviewed these analyses together.

A compensation of 350 rupees (US\$5.50) was offered to participants, although several refused payment. All participants provided oral consent before any data were collected.

\section{RESULTS}

\section{Participants' characteristics}

Twenty-four male pharmacy employees were recruited from 10 urban and rural villages in Haryana. According to survey responses, half of the participants reported a monthly income between US\$150 and US\$374, one-third reported an income of US $\$ 375$ or higher, and the remainder reported an income of $<\mathrm{US} \$ 150$.

\section{Clinical training}

Based on survey responses, only one-quarter of participants had completed a pharmacy degree $(6 / 24)$. The remainder had a wide variety of educational backgrounds, including 1 participant currently pursuing a D Pharm (4\%), 5/24 (21\%) having completed a Bachelor of Arts or Bachelor of Commerce, 7/24 (29\%) having 10th or 12th grade as their highest level of education, 2 participants $(8 \%)$ with Master's degrees in Business Administration and Sociology, and the 3 remaining participants $(12.5 \%)$ currently pursuing a Bachelor's degree in another field. Several untrained employees dispensed medication part-time at the pharmacy of a friend or family member and had a second job or were still in college. These part-time employees were officially hired, paid a salary and consistent over time.

I work in a medical store. [...] This is my brother's medical store. If he is not available, I sit here [and dispense].-Participant 14, Bachelor of Arts

I am a student and work in a medical store on part time basis.-Participant 24, pursuing Bachelor of Engineering

Although respondents knew that a pharmacy degree is a legal requirement for unsupervised pharmacy work, most discussed unlicensed dispensing openly. Many felt that prior work experience under a pharmacist's supervision was an adequate substitute for formal training. In fact, it was common for wealthier people without training to purchase a pharmacy as a business venture, do a brief informal apprenticeship and subsequently begin dispensing at their own shop.

I own a medical store. [...] I worked in a chemist shop. [...Where did you learn about antibiotics?] In the medical store where I got training.-Participant 17, Masters in Business Administration

I own a medical store. [...I trained] by sitting in the medical store $[. .$.$] about two months. [...Before that I$ received training] from another medical store [...] for two months.-Participant 18, 10th grade education 
Since formal training was limited, pharmacy employees frequently relied on doctors, other pharmacists and pharmaceutical literature for clinical diagnostic and treatment recommendations, especially for new clinical presentations.

When we see patients with a newer disease, we check if they have gone previously to an MBBS (Bachelor of Medicine, Bachelor of Surgery) doctor, and if so, what their prior prescription was. We try to remember the prescription and we give medicines accordingly. [...We also get information] from the doctors we know. We contact them, take our patients to them, or send patients to them.-Participant 1, D. Pharm

I have Drug Today (quarterly Indian pharmaceutical magazine), and I also ask for help from my seniors, who are in this field and have taken the formal pharmacy courses.-Participant 21, 12th grade education

\section{Antibiotic knowledge}

Although all employees dispense antibiotics, only half could correctly define the term. Of the 12 who could, 2 had D Pharm training $(2 / 6,33.3 \%)$ and 10 were unlicensed $(10 / 18,55.6 \%, \mathrm{p}=0.6374)$. Two-thirds of employees had not heard of antibiotic resistance (16/ $24,66.7 \%)$ and only four could define the term (4/24, $16.7 \%)$. Most definitions of antibiotics were incorrect because they focused solely on symptomatic treatment.

It is a drug used as antipyrogen.-Participant 7, D Pharm

Antibiotics are used for all diseases, for example, pain, fever, and to dry wounds.-Participant 13, 12th grade education

Survey data collaborated with the pattern of dispensing based on patient symptoms. Over half of the employees thought that using antibiotics was appropriate for treating colds $(10 / 24 ; 58.3 \%), 87.0 \%$ for viral infections (20/23), $66.7 \%$ for coughs $(16 / 24)$ and $70.8 \%$ for sore throat $(17 / 24)$.

Employees' own knowledge of antibiotics affected their willingness to dispense to the $\sim 20 \%$ of patients who requested medications by name. These patients were perceived as more knowledgeable about their health than others, and were thus more likely to receive antibiotics without a prescription.

If someone asks for a medicine by name, then I will give it to them. [Even without a prescription?] Yes. If he asks for it by name then I will dispense it, because he must be knowledgeable about it or have taken it.-Participant 13, 12 th grade education

We get many of such patients [requesting medications by name; What do you do?] I sell the antibiotic.Participant 23, 12th grade education

\section{Healthcare access}

Many villages did not have licensed allopathic doctors; thus, patients often came to pharmacies directly, explained their symptoms and received medical advice and treatment. Pharmacy employees typically advised patients to seek a doctor's consultation, but admitted that this is often not practical.

The main problem here is that there is no hospital or MBBS doctor in this village. People come to the medical store for treatment to save money, because otherwise they think that they will have to go far away.-Participant 1, D Pharm

Although prescriptions are legally required to purchase antibiotics, all employees reported treating common illnesses and mild infections without prescriptions. Several participants were unaware of the nationwide 2014 Schedule H1 restrictions, which amend the 1945 Drugs and Cosmetic Rules and increase the level of documentation required for dispensing 46 antibiotic medications. ${ }^{34}$ Employees typically recommended that patients consult a physician for more serious cases.

I only give treatment to those with illnesses that I think I can handle. Otherwise, I do not see patients. [...] First, I check the symptoms. If I feel that it is necessary, then I give medications. If the patient is serious, I ask him or her to consult the doctor--Participant 5, pursuing Bachelor of Arts

In serious conditions, I refer them to the doctor. I give medicine when the condition is not serious, like fever and diarrhea.-Participant 11, D Pharm

Another key provider of medical care in villages was unlicensed rural medical practitioners (RMP). RMPs have no clinical training and cannot legally provide healthcare advice or dispense antibiotics. Pharmacy employees had mixed opinions regarding the care patients receive from unlicensed practitioners. Some spoke despairingly of them, while others recognised their importance in areas of limited healthcare access.

The physician is at least an MBBS. I refuse for my patients to go to quacks [RMPs].-Participant 21, 12th grade

People do not know about it [resistance]. Quacks [RMPs] are writing it and antibiotic resistance is developing. The doctors [RMPs] are writing powerful antibiotics. -Participant 15, D Pharm

Nearby all the RMPs are okay, but there are no MBBS doctors.-Participant 7, D Pharm

\section{Shorter than recommended antibiotic course}

Overall, $85 \%$ of employees sold abbreviated antibiotic courses, often just 1-2 days of tablets $(17 / 20)$. The frequency of this practice varied across providers, but 
occurred on average in $\sim 50 \%$ of antibiotic purchases, primarily for poorer clientele who could not afford a complete dose. Although patients were recommended to return to purchase the rest of the medication, they rarely did.

[Short dispensing is] always due to money issues. Suppose the doctor has prescribed Augmentin, which is 200 rupees for ten tablets. Patients will ask for two tablets initially, and I will give two tablets. [How often?] Seventy percent of the time [How many return?] Ten percent.Participant 15, D Pharm

Participants reported strong pressure from patients to dispense short antibiotic courses. Although they recognised that this was risky and advised purchasing the full dose, ultimately many employees still dispensed as requested.

There are many poor patients who are not able to buy medicine. They ask for a single tablet. [How often?] Twenty-five percent come and buy two tablets. [..] I explain to them that they will not be cured with this, and that they should either go to a doctor or buy medicine for two more days. If they agree, then fine. If they don't agree, then I have to dispense according to their demands. Participant 7, D Pharm

It happens if they do not have enough money. If they have enough money, then they will buy the complete course. [How often?] It happens in about sixty percent of the cases. [...] I sell him the medicine according to his demands. For example, if he asks for one day, then I sell a one-day supply.-Participant 21, 12th grade education

However, some employees had developed alternative methods of dispensing. Of note, several reported selling medicine on credit and taking the financial burden on themselves.

Many times people say, I do not have this much money. I ask them to give whatever money they have [...] I do it on humanitarian grounds. I ask them to give me the remaining money later on. Your course should not be incomplete-Participant 13, 12th grade education

Sometimes I sell on rate, without charging my profit. Participant 24, pursing Bachelors of Engineering

\section{Expired or near-expired medications}

Finally, we asked employees about economic pressures to overdispense expiring antibiotics. Selling drugs nearexpiry was a highly atypical practice among employees in our study. In fact, many were adamant about not selling these medications and found the procedure for returning medications straightforward.

It is like playing with the life of the patient. [...] If it is going to expire than I can always return it. [...Drug representatives] come every week. I know which medicines are going to expire, so I get the company to replace the near expiry drugs with long expiry stock. [Is it difficult?] This process is good. No problem at all.Participant 9, Bachelors of Arts

Medicines are returned. Why give it to the customer? The expired medicines do not have the same effect as that of fresh stock. We never sell like that. [...To return stock] we note it down and return it to the stockist. The same amount is either adjusted in a new bill or we get new stock as replacement.-Participant 15, D Pharm

The barriers that did exist to this process were primarily financial. Employees return medications back to their supplier at a cost. Some employees viewed this as an unavoidable part of pharmacy practice, while others found it more concerning.

We cannot give expired medicines to the people. Profit and loss are normal-Participant 21, 12th grade

All expired or nearing expiry medicines are returned in the first ten days of every month. When the distributor comes to supply a new order, the expired or nearing expiry medicines are returned at that time. [Is this difficult?] Yes. [Why?] The distributor deducts some amount of money from the total value of the expired or nearing expiry medicines. Participant 20, Bachelors of Commerce

\section{DISCUSSION}

In this study of village pharmacy employees, we found that the majority of practitioners lacked formal clinical training and adequate knowledge of antibiotic resistance. Both findings have implications for perpetuating antibiotic misuse and increasing endemic levels of resistance in villages in India and worldwide. Only $25 \%$ of participants were licensed pharmacists. In accordance with nationwide trends, they obtained the D Pharm, not B Pharm or graduate pharmacy degrees. ${ }^{9}$ While the low proportion of trained pharmacists in India is consistent with news reports, ${ }^{35}{ }^{36}$ few research studies have conducted formal evaluations of pharmacists' educational experiences. However, one existing study in India and two in neighbouring Pakistan found similarly low rates of licensing among those dispensing medicines. ${ }^{28} 37 \quad 38$ The Indian study, which comprehensively surveyed all pharmacies in Ujjain district, found that only $11.58 \%$ had clinical training. ${ }^{37}$ This lower proportion of licensing compared with our results is expected, given that training among healthcare workers decreases as villages become increasingly rural, ${ }^{3}$ and all villages we surveyed were within $30 \mathrm{~km}$ of the major city of Gurgaon.

Although all employees dispensed antibiotics, only half could correctly define the term. This finding highlights well-established concerns with the quality of pharmacy training curriculums in India. First, much of the current training provided to students is outdated, as national standards for the D Pharm curriculum were last released in $1991 .^{39}$ This represents a knowledge gap of 
over two decades. Revisions to the curriculum are much needed. While an updated D Pharm curriculum was expected in 2016, none has been implemented until now. Second, the quality of pharmacy education ranges widely across institutions. ${ }^{9}$ Admission to programmes at public universities is competitive, but admission to private institutions varies extensively, as does the quality of training once enrolled. Finally, there are no requirements for pharmacists to participate in continuing pharmacy education. ${ }^{9}$ Thus, only recent graduates are likely to have received adequate training on emerging topics like multidrug resistant organisms and endemic antibiotic resistance. Continuing pharmacy education requirements, standard in many countries globally, are a natural extension of pharmacy training and could fill in the knowledge gaps that many licensed pharmacists report. Their enactment should be seriously considered by national lawmakers and pharmacist organisations.

All interviewed employees in our study reported dispensing antibiotics without a prescription. This was especially common among patients who could not afford the fees and travel costs of a doctor's consultation. Even employees holding a D Pharm are not trained in clinical diagnosis; thus, this practice results in overuse when antibiotics are dispensed to treat conditions such as the common cold, viral fevers and mild diarrhoea, for which they are not effective or necessary. Other studies from across India corroborate that dispensing without prescription is extremely common. ${ }^{25} 294041$ Among 24 pharmacies in Tamilnadu, $78.7 \%$ of antibiotics were dispensed without a prescription, with half requested by the client and half on the pharmacist's recommendation. ${ }^{40}$ In a study of 261 urban Bangalore pharmacies, antibiotics were offered without prescription $66.7 \%$ of the time. Furthermore, among the 87 pharmacies that did not offer antibiotics, only $16(18.4 \%)$ cited no prescription as the reason for not dispensing. ${ }^{29}$ Finally, none of the 40 New Delhi pharmacists in Kotwani et $a l \mathrm{~s}^{25}$ study refused to sell antibiotics without a prescription.

As with antibiotic overuse, underuse also occurred most often among poorer patients. In our study, $85 \%$ of employees reported selling shorter than recommended antibiotic courses. This practice is most likely closely related to several other factors we investigated, including employee's antibiotic knowledge, attitudes, experience and patient's economic status. In fact, most participants considered dispensing shortened courses to be a charitable action. Studies investigating the length of antibiotic courses show similar results in low-income and middle-income countries around the globe. A study of 1524 patients in Manila, Philippines found that only $10 \%$ purchased more than 10 antibiotic tablets, with 2 being most common. ${ }^{26}$ In rural Matlab, Bangladesh, $48 \%$ of patients purchased 1-3 tablets of antibiotics tetracycline, penicillins, sulfonamides and chloramphenicol. ${ }^{42}$ In India, our results closely parallel Kotwani et als findings that pharmacists dispense according to patients' economic status and often sell between four and six antibiotic tablets for mild infections. As in our study, these pharmacists were largely unaware of the dangers of incomplete courses and considered providing medication, regardless of how much, to be their social responsibility. ${ }^{25}$

Kotwani et al also revealed that New Delhi pharmacists felt economic pressures to dispense and had difficulty returning medications to distributors. Together, these barriers led to overdispensing of expired or near-expired medications. ${ }^{25}$ We assessed this practice in our study, but found starkly different results. Village pharmacy employees consistently reported little pressure to overdispense expiring medications and described a simple process for returning medications to distributors. While social desirability bias is a potential reason for the discrepancy, we took particular care to minimise it in these discussions. We cited the New Delhi study results during the interview, in an attempt to normalise economic pressures and inappropriate dispensing practices. Thus, we believe that experiences regarding expiring medications are indeed different in urban and village populations. This is potentially due to stronger pharmacy-patient relationships in village settings, where employees may be less willing to risk poor outcomes for a friend or neighbour. Furthermore, distributors typically visited individual village pharmacies frequently, during which times employees could return medications directly.

Additional study limitations include the all male study population. This resulted from our non-random, convenience sampling method of recruitment. While this gender composition is representative of the pharmacies we identified, female pharmacy employees may have different knowledge, attitudes and practices regarding antibiotic dispensing. Future pharmacy studies of antibiotic practices should target recruitment of female employees. The quantitative portion was conducted as a pilot study to assess the feasibility of conducting our survey in the field and our results are most likely not representative of the greater Haryana or nationwide village pharmacy employee population. Nevertheless, our findings are highly consistent with other existing studies from India and Pakistan. ${ }^{25} 282937384041$

In an effort to promote practical antibiotic policies, the WHO and several leading Indian medical, pharmacy and research societies developed the Chennai Declaration in 2012. ${ }^{43}$ This 5-year plan focuses on enforcement of antibiotic restrictions that are realistic and implementable in India's current healthcare context. Despite low levels of antibiotic knowledge, pharmacy employees should not be overlooked as key contributors to such efforts. They have a unique role in villages to provide essential front-line care. As seen in India's expansion of direct observed treatment for tuberculosis, large numbers of pharmacy employees with minimal baseline tuberculosis knowledge were highly willing to undergo targeted clinical training. These programmes have increased both access and quality of 
tuberculosis therapy in India since their inception. ${ }^{44}$ Providing both licensed and unlicensed pharmacy employees a free, intensive, short-term, training programme focused on proper antibiotic dispensing and the identification of common conditions that require antibiotics has the potential to greatly reduce inappropriate dispensing in village communities. Including licensed pharmacists in a training programme is important, given the lack of continuing pharmacy education requirements in India and the clinical expertise that trained pharmacists provide to non-trained employees within local communities. Future studies should be conducted to evaluate the most effective methods of training to accomplish this in the context of rural India.

\section{CONCLUSIONS}

As the primary antibiotic gatekeepers, pharmacies are key stakeholders in the reduction of antibiotic resistance in India. We found that employees in our sample reported overdispensing and underdispensing antibiotics. This was due in part to their desire to provide care to all patients, regardless of income, and providers' limited understanding of the drivers of antibiotic resistance. These findings reinforce the importance of developing and instituting an antibiotic training programme for pharmacy employees in India's villages and for the immediate revision of $\mathrm{D}$ Pharm curriculums on a national level. Such efforts are essential to preventing antibiotic misuse at the source and slowing the current rise of antibiotic resistance globally.

\section{Author affiliations \\ ${ }^{1}$ Department of Population Health Sciences, University of Wisconsin, School of Medicine and Public Health, Madison, Wisconsin, USA \\ ${ }^{2}$ Medanta Institute of Education and Research, Medanta the Medicity Hospital, Gurgaon, Haryana, India \\ ${ }^{3}$ Department of Clinical Microbiology \& Infection Control, Medanta the Medicity Hospital, Gurgaon, Haryana, India \\ ${ }^{4}$ Department of Medicine, University of Wisconsin, School of Medicine and Public Health, Madison, Wisconsin, USA \\ ${ }^{5}$ William S. Middleton Memorial Veterans Affairs Hospital, Madison, Wisconsin, USA}

Acknowledgements The authors acknowledge Pooja Sharma, MBBS, MD (Senior Scientist, Medanta the Medicity Hospital) for her help with survey development and facilitating successful implementation of the study and Sazid Alam, MSc (Medanta the Medicity Hospital) for his help with survey development and data collection. The authors also acknowledge Ajay Sethi, PhD (University of Wisconsin-Madison) and Karishma Desai, PhD, B Pharm (Stanford University) for their help with survey development.

Contributors AKB drafted and edited the manuscript, and contributed to study conception, design, data acquisition and data analysis. KB and MA contributed to data collection, data analysis and critical manuscript editing. SS and NS contributed to the study design and critical manuscript editing. All authors read and approved the final version of this manuscript.

Funding The research presented was supported under NIH awards UL1TR000427 and TL1TR000429, the Indo-US Science and Technology Forum S. N. Bose Scholars Program, and a Graduate Student Award from the Global Health Institute at the University of Wisconsin, Madison.

Competing interests None declared.
Ethics approval The Institutional Review Board at Medanta the Medicity Hospital approved this study. The Institutional Review Board at the University of Wisconsin granted this study exemption from review.

Provenance and peer review Not commissioned; externally peer reviewed.

Data sharing statement No additional data are available.

Open Access This is an Open Access article distributed in accordance with the Creative Commons Attribution Non Commercial (CC BY-NC 4.0) license, which permits others to distribute, remix, adapt, build upon this work noncommercially, and license their derivative works on different terms, provided the original work is properly cited and the use is non-commercial. See: http:// creativecommons.org/licenses/by-nc/4.0/

\section{REFERENCES}

1. Physicians (per 1,000 people). The World Bank. 2012. http://data. worldbank.org/indicator/SH.MED.PHYS.ZS (accessed Apr 2016).

2. Increasing access to health workers in remote and rural areas through improved retention. World Health Organization. 2010. http:// www.searo.who.int/nepal/mediacentre/2010_increasing_access_to_ health_workers_in_remote_and_rural_areas.pdf (accessed May 2016).

3. Das J, Holla A, Das V, et al. In urban and rural India, a standardized patient study showed low levels of provider training and huge quality gaps. Health Aff (Millwood) 2012;31:2774-84.

4. Bagcchi S. India has low doctor to patient ratio, study finds. BMJ 2015;351:h5195.

5. Kamat VR, Nichter M. Pharmacies, self-medication and pharmaceutical marketing in Bombay, India. Soc Sci Med 1998;47:779-94.

6. Sharma $\mathrm{H}$, Jindal $\mathrm{D}$, Aquil $\mathrm{M}$, et al. A survey for assessment of the role of pharmacist in community pharmacy services. J Pharm Bioall Sci 2009;1:23-6.

7. Ganguly NK, Arora NJ, Chandry SJ, et al. Rationalizing antibiotic use to limit antibiotic resistance in India. Indian J Med Res 2011;134:281-94.

8. Basak SC, van Mil JW, Sathyanarayana D. The changing roles of pharmacists in community pharmacies: perception of reality in India. Pharm World Sci 2009;31:612-8.

9. Basak SC, Sathyanarayana D. Pharmacy education in India. Am $J$ Pharm Educ 2010;74:68.

10. World Health Organization. Antimicrobial resistance: global report on surveillance. World Health Organization. 2014. http://www. who.int/drugresistance/documents/surveillancereport/en/ (accessed Nov 2014).

11. Centers for Disease Control and Prevention. Antibiotic resistance threats in the United States. Centers for Disease Control. 2013. http://www.cdc.gov/drugresistance/threat-report-2013/ (accessed Nov 2014).

12. Department of Health and Department for Environmental Food and Rural Affairs. UK five year antimicrobial resistance strategy, 2013 to 2018. Department of Health and Department for Environmental Food and Rural Affairs. 2013. https://www.gov.uk/government/publications/ uk-5-year-antimicrobial-resistance-strategy-2013-to-2018 (accessed Feb 2016)

13. Ghafur A, Mathai D, Muruganathan A, et al. The Chennai declaration: a roadmap to tackle the challenge of antimicrobial resistance. Indian J Cancer 2013;50:71-3.

14. World Economic Forum. Declaration by the pharmaceutical, biotechnology and diagnostics industries on combating antimicrobial resistance. World Economic Forum, Davos Switzerland. 2016. http:// amr-review.org/sites/default/files/Declaration_of_Support_for_ Combating_AMR_Jan_2016.pdf (accessed Feb 2016).

15. Allegranzi $\bar{B}$, Bagheri Nejad S, Combescure $C$, et al. Burden of endemic health-care-associated infection in developing countries: systematic review and meta-analysis. Lancet 2011;377:228-41.

16. Laxminarayan $R$, Duse $A$, Wattal $C$, et al. Antibiotic resistance-the need for global solutions. Lancet Infect Dis 2013;13:1057-98.

17. Duane S, Domegan C, Callan A, et al. Using qualitative insights to change practice: exploring the culture of antibiotic prescribing and consumption for urinary tract infections. BMJ Open 2016;6:e008894.

18. Crowson MG, Schulz KC, Tucci DL. Provider and patient drivers of ototopical antibiotic prescription variability. Am J Otolaryngol 2015;36:814-19.

19. Butler CC, Rollnick S, Pill R, et al. Understanding the culture of prescribing: qualitative study of general practitioners' and patients' perceptions of antibiotics for sore throats. BMJ 1998;317:637-42. 
20. Nyquist AC, Gonzales R, Steiner JF, et al. Antibiotic prescribing for children with colds, upper respiratory tract infections, and bronchitis. JAMA 1998;279:875-7.

21. Llor C, Monnet D, Cots J. Small pharmacies are more likely to dispense antibiotics without a medical prescription than large pharmacies in Catalonia, Spain. Euro Surveill 2010;15:pii:19635.

22. Roque F, Soares S, Breitenfeld L, et al. Influence of community pharmacists' attitudes on antibiotic dispensing behavior: a cross-sectional study in Portugal. Clin Ther 2015;37:168-77.

23. Zapata-Cachafeiro M, Gonzalez-Gonzalez C, Vaquez-Lago JM, et al. Determinants of antibiotic dispensing without a medical prescription: a cross-sectional study in the north of Spain. $J$ Antimicrob Chemother 2014;69:3156-60.

24. Roque F, Soares S, Breitenfeld L, et al. Attitudes of community pharmacists to antibiotic dispensing and microbial resistance: a qualitative study in Portugal. Int J Clin Pharm 2013;35:417-24.

25. Kotwani A, Wattal C, Joshi PC, et al. Irrational use of antibiotics and role of the pharmacist: an insight from a qualitative study in New Delhi, India. J Clin Pharm Ther 2012;37:308-12.

26. Lansang MA, Lucas-Aquino R, Tupasi T, et al. Purchase of antibiotics without prescription in Manila, the Philippines. Inappropriate choices and doses. J Clin Epidemiol 1990;43:61-87.

27. Strum AW, van der Pol R, Smits AJ, et al. Over-the-counter availability of antimicrobial agents, self-medication and patterns of resistance in Karachi, Pakistan. J Antimicrob Chemother 1997;39:543-7.

28. Rabbani F, Cheema FH, Talati N, et al. Behind the counter: pharmacies and dispensing patterns of pharmacy attendants in Karachi. J Pak Med Assoc 2001;51:149-53.

29. Shet A, Sundaresan S, Forsberg BC. Pharmacy-based dispensing of antimicrobial agents without prescription in India: appropriateness and cost burden in the private sector. Antimicrobial Resist Infect Control 2015;4:55.

30. Lim KK, Teh CC. A cross sectional study of public knowledge and attitude towards antibiotics in Putrajaya, Malaysia. South Med Rev 2012;5:26-33.

31. Chen $\mathrm{C}$, Chen YM, Hwang KL, et al. Behaviour, attitudes and knowledge about antibiotic usage among residents of Changhua, Taiwan. J Microbiol Immunol Infect 2005;38:53-9.

32. Shehadeh M, Suaifan G, Darwish R, et al. Knowledge, attitudes and behavior regarding antibiotics use and misuse among adults in the community of Jordan. A pilot study. Saudi Pharm J 2012;20: 125-33.

33. Parimi N, Pereira LM, Prabhakar P. Caregivers' practices, knowledge and beliefs of antibiotics in paediatric upper respiratory tract infections in Trinidad and Tobago: a cross sectional study. BMC Fam Pract 2004;5:28.

34. G.S.R. 588(E). Ministry of Health and Family Welfare. Department of Health and Family Welfare. 2013. http://www.egazette.nic.in/ WriteReadData/2013/E_441_2013_024.pdf (accessed Apr 2016).

35. Pearl D, Stecklow S. Drug firms' incentives fuel abuse by pharmacists in India. The Wall Street Journal. 16 August 2001. http:// www.wsj.com/articles/SB997910373349012375 (accessed Apr 2016).

36. Karlikar N. FDA officials crack the whip on medical shops sans pharmacist. The Times of India. 28 February 2014. http:// timesofindia.indiatimes.com/city/thane/FDA-officials-crack-thewhip-on-medical-shops-sans-pharmacist/articleshow/31132361.cms (accessed Apr 2016).

37. Sabde YD, Diwan V, Saraf VS, et al. Mapping private pharmacies and their characteristics in Ujjain district, Central India. BMC Health Serv Res 2011;11:351.

38. Butt ZA, Gilani AH, Nanan D, et al. Quality of pharmacies in Pakistan: a cross-sectional survey. Int J Qual Health Care 2005;17:307-13.

39. Pharmacy Council of India. Education regulations 1991-chapter 2. Ministry of Health \& Family Welfare, Govt. of India. 2010. http://www. pci.nic.in/RulesRegulations/EducationRegulations1991/Chapter2. aspx (accessed Nov 2016).

40. Basak SC, Sathyanarayana D. Evaluating medicines dispensing patterns at private community pharmacies in Tamilnadu, India. South Med Rev 2010;3:27-31.

41. Rathnakar UP, Sharma NK, Garg R, et al. A study on the sale of antimicrobial agents without prescriptions in pharmacies in an urban area of South India. J Clin Diagn Res 2012;6:951-4.

42. Hossain MM, Glass RI, Khan MR. Antibiotic use in a rural community in Bangladesh. Int J Epidemiol 1982;11:402-5.

43. Ghafur A, Mathai D, Muruganathan A, et al. The Chennai Declaration: a roadmap- to tackle the challenge of antimicrobial resistance. Indian J Cancer 2013;49:84-94.

44. Pharmacies in national TB programme in India: a new era. International Pharmaceutical Federation. 2015. https://www.fip.org/ files/fip/news/DOTS_TB_projectIndia.pdf (accessed May 2016). 